\title{
SYSTEM OF INTEGRATED ENERGY SUPPLY OF SEPARATE FACILITIES FROM RENEWABLE ENERGY SOURCES
}

\author{
N. Stoyanov ${ }^{\text {a* }}$, D. Abornev ${ }^{\text {b }}$, S. Smirnov ${ }^{\text {b }}$, A. Stoyanov ${ }^{c}$ \\ a * Associate Professor, PhD in Engineering sciences, North Caucasus Federal University, 1, Pushkin Street, Stavropol, 355009, \\ Russian Federation, e-mail: stoyanov.ac.p@mail.ru \\ ${ }^{\mathrm{b}}$ Candidate of Engineering sciences, Associate Professor, North Caucasus Federal University, 1, Pushkin Street, Stavropol, 355009, \\ Russian Federation \\ ${ }^{\text {c } M a s t e r ' s ~ D e g r e e ~ s t u d e n t, ~ N o r t h ~ C a u c a s u s ~ F e d e r a l ~ U n i v e r s i t y, ~ 1, ~ P u s h k i n ~ S t r e e t, ~ S t a v r o p o l, ~ 355009, ~ R u s s i a n ~ F e d e r a t i o n ~}$
}

Received: 01.10.2017 / Accepted: 15.10.2017 / Revised: 27.11.2017 / Available online: 15.12.2017

\section{DOI: 10.1515/jaes-2017-0014}

KEY WORDS: integrated power supply of separate facilities, renewable energy sources, alternative energy

\begin{abstract}
:
The relevancy of the study is due to low efficiency of using solar and geothermal energy in the existing process schemes. In this regard, this article is aimed at revealing the possibilities of using solar and geothermal energy for the integrated energy supply of separate facilities from renewable energy sources. The mathematical simulation method based on the theory of graphs of energy system operation, which makes it possible to analyze the efficiency of the integrated use of solar and geothermal energies for the heat-cold supply of separate facilities, is the main approach to studying this problem. Energy consumption throughout the year and the emergency energy source capacity in "peak" modes were determined based on the developed mathematical model of managing the system of integrated power supply of separate facilities from renewable energy sources plotted with the use of the theory of graphs. The article materials are of practical value for the designers of the systems of integrated heat-cold supply of separate facilities.
\end{abstract}

\section{INTRODUCTION}

The possibilities of using ubiquitous ecologically clean renewable energy of solar radiation and geothermal sources attract increasingly greater attention. According to forecasts, renewable sources of energy (solar energy, geothermal energy, wind energy, biomass energy) should take a prominent position in the total global energy balance within the next $15-20$ years, ensuring the replacement of dwindling organic fuel reserves and ecological recovery of the environment (Decree of the Government of the Russian Federation as of August 28, 2003 No.1234-r; Perminov, 1993; Khavanov. 2003).

Solar radiation "brings" the energy being roughly equivalent to about $100-150 \mathrm{~kg}$ of reference fuel per square meter by year to the Earth's surface on an average by year in the conditions of Russian midland. The practical task facing developers and creators of various types of solar plants is to most effectively convert solar energy to the required type of energy (heat, electrical power) with the lowest installation costs (Stoyanov, $2014 \mathrm{a}, \mathrm{b}$ ).

The energy potential of a technically accessible, economically feasible and environmentally friendly geothermal energy source for the needs of heat supply is 44.6 trillion tons of reference fuel (mode $70 / 20^{\circ} \mathrm{C}$ ), including 16.4 trillion tons of reference fuel for heating
(Boguslavsky, 1994; Gnatus, 2012; Ryzhenkov, 2009; Alkhasov, 2008).

The lack of energy costs for fuel supply in the process of operation, which significantly reduces the expenditure side, is the variation of the most part of renewable energy plants from traditional plants. The costs of equipment production as well as construction of buildings and structures are the main items of energy expenditure while developing and operating such facilities. Moreover, the construction of any facilities is often not required for low power plants; therefore this expense item is not always present.

The European Union plans to receive $50 \%$ of all necessary energy using renewable energy sources (RES) by the year 2040, which should ensure environmental safety and future development. The rates of alternative RES development in industrialized countries show that they will be able to replace up to $70 \%$ of traditional energy supply by the year 2050 .

The use of heat pumps for utilization efficiency improvement of renewable energy sources is a promising trend in a number of European countries (Stoyanov, 2013).

As theoretical studies have shown, the use of solar energy is fulfilled for the purposes of hot water supply only, and the solar energy collector potential is not utilized completely, as 
well as the potential of solar energy collectors is insufficient for heating systems in the winter time (Designer's Handbook. Part I: Heating, 1991). Since some types of energy consumption have strongly-pronounced variations by months of a year (heating, ventilation and air conditioning), and others have strongly-pronounced variations by the hours of a day (electricity and hot water supply), the plant for use of renewable energy sources must have a power reserve in order to serve the "peak" loads and a heat accumulator (Shishkin, 2004; Pleshka et.al., 1990; Sotnikova, 2009).

\section{MATERIAL AND METHODS}

The process scheme of the energy complex for the year-round integrated power supply of a building (heating, air conditioning and hot water supply) has been developed with consideration for the effective use of the system power. The developed energy complex process scheme for heat-and-cold supply system being effective when using heat pump systems is shown in Figure 1.

The schema includes the following elements: hybrid solar collector; electric energy converter; inverter vapor compressor heat pump; heat-removing pipes of inverter vapor compressor heat pump; petrothermal well; substance with a phase-transition temperature of $20-43^{\circ} \mathrm{C}$; cracks formed by hydrofracturing filled with a substance with a phasetransition temperature of $20-43^{\circ} \mathrm{C}$; heat accumulator; electric accumulator; room (heat consumer for heating and hot water supply systems, user of refrigeration for air conditioning system); absorption heat pump; bivalent hot-water generator. The following flows as electric energy, heat transfer fluid, and tap water for hot-water supply system are shown as well.

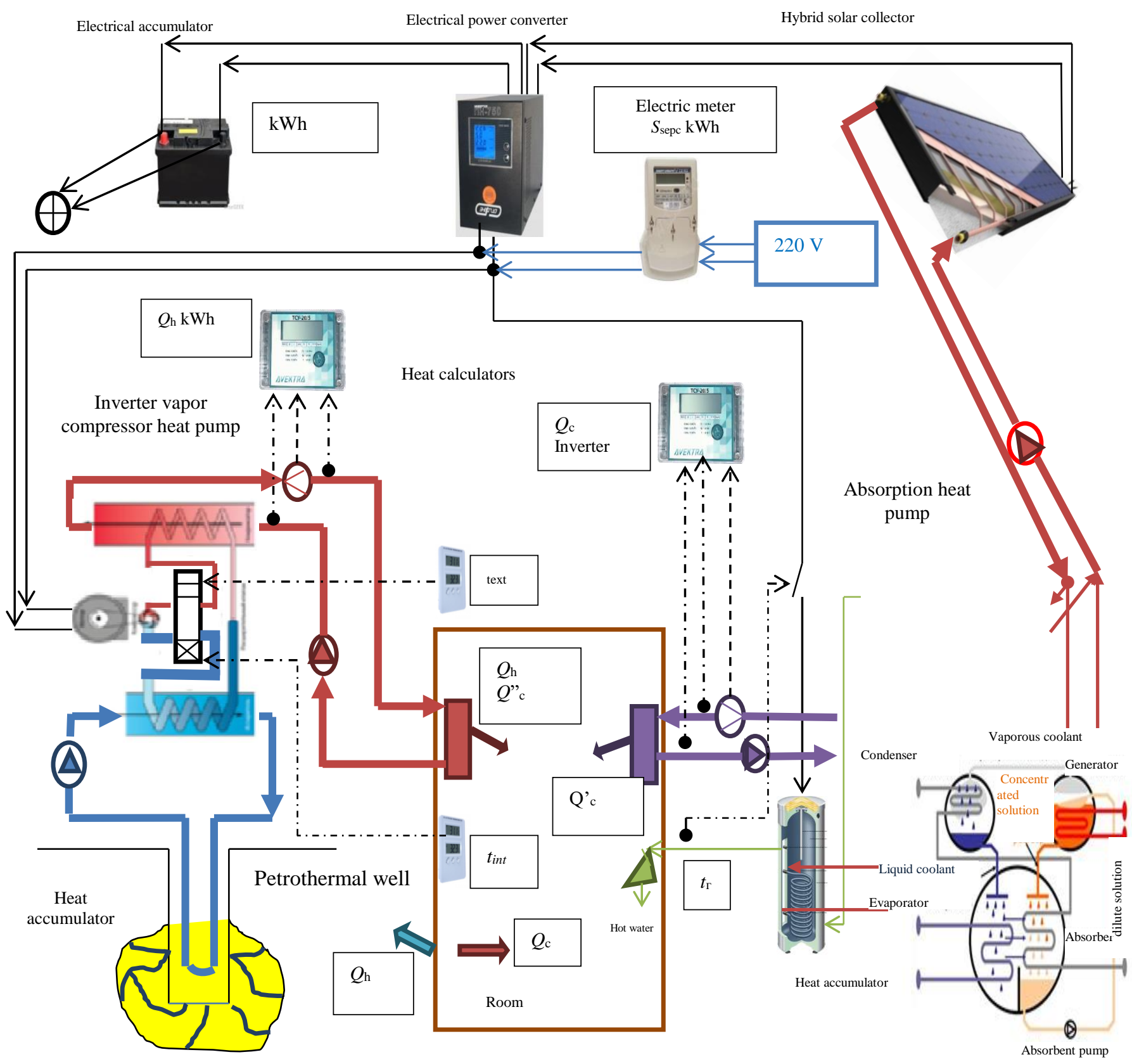

Figure 1. System of integrated energy supply of separate facilities from renewable energy sources 
Flow symbols on the diagram:

$Q_{\text {c }}$ load on the conditioning system in the warm period,

$\mathrm{W}$;

$Q_{\mathrm{h}}$ - load on the heating system in the cold period, W;

$Q^{\prime}$ c - cold output for the conditioning system by means of absorption heat pump, W;

$Q{ }^{\prime}$ c - cold output for the conditioning system with the help of inverter vapor compression heat pump, W;

$S$ sepc - electric power consumption from a backup source with an insufficient solar collector power, $\mathrm{kWh}$;

$t_{\text {int }}$ - room design temperature, ${ }^{\circ} \mathrm{C}$;

$t_{\mathrm{h}}$ - hot water design temperature in the hot-water supply system, ${ }^{\circ} \mathrm{C}$.

Fractures are being formed via hydraulic fracturing in a petrothermal well with the depth of down to $100 \mathrm{~m}$ at a depth below $15-20 \mathrm{~m}$, and a substance with a phase transition temperature of $20-43^{\circ} \mathrm{C}$ (for example, mirabilite (Glauber's salt): melting temperature $20-32^{\circ} \mathrm{C}$, melting heat (phase transition) $251 \mathrm{~kJ} / \mathrm{kg}$ ) or paraffin: melting temperature $43^{\circ} \mathrm{C}$, melting heat (phase transition) $209 \mathrm{~kJ} / \mathrm{kg}$ ) is being pumped into the above-mentioned fractures, and thus a heat accumulator is being created.

In the warm period, the electrical energy produced by the hybrid solar collector enters into the electric energy converter, wherefrom it enters into the inverter vapor compression heat pump, and it enters into the electrical accumulator in case of excessively generated electric energy. Excessively generated electrical energy being accumulated in the electrical accumulator can then be used at night time for "on-duty" lighting. Besides, the electrical energy is used for "peak" finish heating a tap water in a hot water supply system in a bivalent water heater in case of an insufficient thermal power of a hybrid solar collector. The inverter vapor-compressor heat pump is used for room air-conditioning system via heat transfer medium of the vapor-compression heat pump. In this case, the room air conditioning heat is simultaneously pumped via heat carrier from the condenser of the inverter vapor compressor heat pump into the heat accumulator (including the petrothermal well layer) with a substance having a phase transition temperature of $20-43^{\circ} \mathrm{C}$. Heat carrier of the inverter vapor compression heat pump is fed into the petrothermal well via the heat-removable tubes of the inverter vapor compression heat pump and exchanges heat with the heat accumulator. In the cold period, the electrical energy produced by the hybrid solar collector is used via the inverter vapor compressor heat pump by means of the heat carrier of the heat-removing pipes of the inverter vapor compressor heat pump to supply heat from the heat accumulator and the layer (petro-thermal energy) to the room heating system. Thus, the heat accumulator "smoothest out" the unevenness of the thermal energy supply and consumption. Regulation of the complex thermal rates is being fulfilled from the sensors: $t_{\text {int }}-$ room temperature; $t_{e x t}-$ outdoor temperature; $t_{\mathrm{h}}-$ hot water heating temperature.

Heat of the hybrid solar collector is used via the hybrid solar collector circuit heat carrier as follows: it is applied in a bivalent hot-water generator for heating the tap water in the hot-water supply system during warm and cold periods, as well as it is applied in the absorption heat pump for generating cold in the room air conditioning system during warm period by means of absorption heat pump coolant. Heat carrier, which has given up its heat in the bivalent water heater and absorption heat pump, is returned to heat into a hybrid solar collector.

Electrical energy being excessively generated via a hybrid solar collector is accumulated in an electric accumulator and can be used at night for "on duty" lighting.

In case of a hybrid solar collector insufficient power, the system is connected to an external energy source. In this case, using an inverter vapor compressor pump, this energy is used more efficiently than in case of "direct" heating in the heating system.

Intended purpose: buildings with a variable thermal rate, i.e. with a thermal regime maintained not within 24 hours, but during working hours only (market and retail shopping centers, administrative buildings). During non-working hours, the temperature in the premises of such a purpose can be maintained at a lower level in the cold period, and it can be maintained at a higher level in the warm period based on the temperature established by regulatory documents (construction rules and regulations) (Stoyanov, 2015a, b; Stoyanov, 2016).

Mathematical model for controlling a system of integrated energy supply of separate facilities from renewable solar and petrothermal energy sources (Figure 2) (Cherednikova and Zemlyakova, 2011; Sidelnikov, 2004; Stoyanov, 2016) has been developed based on the theory of graphs. Mathematical models of the heat supply system are being constructed both based on averaging the thermal conductivity equations, and the heat balance equations. The averaged values of the heat carrier temperature within the system elements are applied as the mode parameters (Cherednikova and Zemlyakova, 2011). The theory of graphs is applied in the paper (Sidelnikov, 2004) with regard to structural-functional models of renewable energy sources.

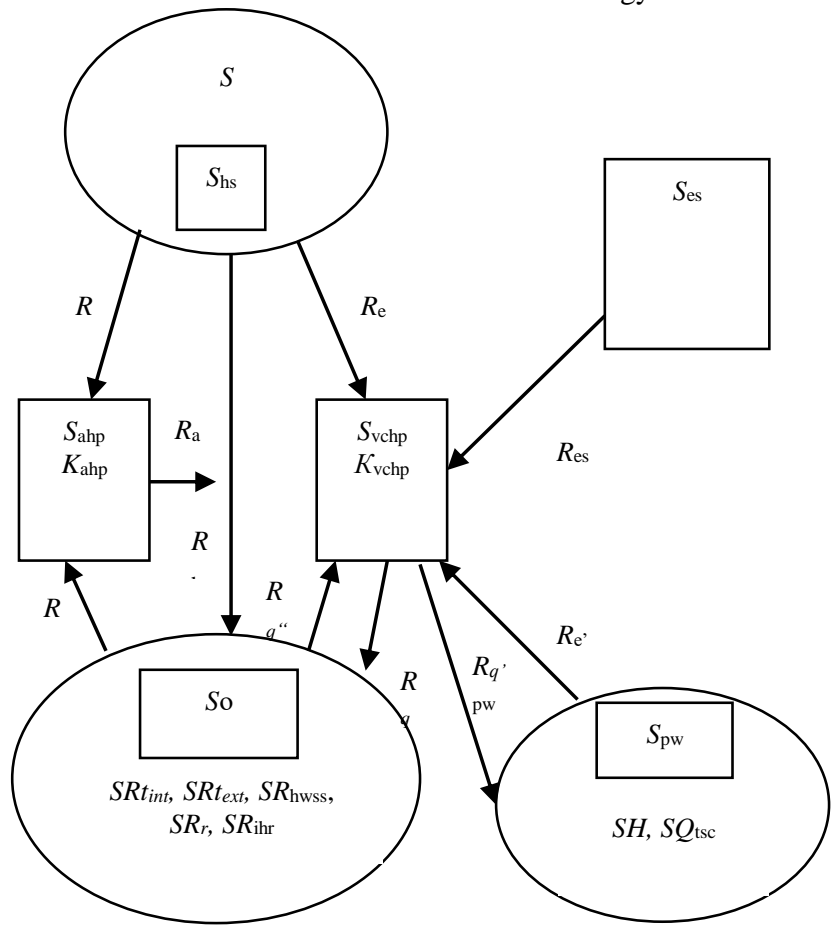

Figure 2 . The graph of power supply system operation from renewable energy sources 
where:

$S_{\mathrm{o}}$ - energy consumer (separate facility);

$S_{\text {hsc, }} S_{\mathrm{pw}}, S_{\mathrm{es}}-$ energy sources, hybrid solar collector, petrothermal well, electrical system, respectively;

$S_{\text {ahp }}, S_{\text {vchp }}$ - heat transformers, absorption heat pump and vapor compressor heat pump, respectively;

$S R t_{\text {int }}, S R t_{\text {ext }}, S R_{\mathrm{hwss}}, S R_{r}, S R_{\mathrm{sr}}, S R_{\mathrm{ihr}}, S H, S Q_{\mathrm{acc}}-$ disturbing actions, room temperature, outdoor temperature, load on the hot water supply system, thermal resistance of the building envelopes, solar radiation, internal heat releases, depth of the petrothermal well, thermal storage capacity of the petrothermal well, respectively;

$K_{\text {ahp }}, K_{\text {vchp, }}$ - heat transformation factors of absorption heat pump and vapor-compressor heat pump, respectively;

$R_{q}, R_{q}$, $R_{\mathrm{hws}}, R_{\mathrm{qpw}}, R_{q}{ }^{\text {'pw }}, R_{q}{ }^{\prime}, R_{\mathrm{e}}$ ', $R_{\mathrm{ahp}}$ - thermal energy fluxes; $R_{\mathrm{e}}, R_{\mathrm{es}}$ - electric energy fluxes from hybrid solar collector and external network, respectively.

The objective function (the capacity of the backup power source for serving the "peak" loads) shall be determined based on the scheme heat balance for the design period:

$$
\frac{d R_{e s}}{d \tau}=\frac{Q S_{e s}}{\kappa_{v c h p} p_{\tau}}
$$

where:

$Q S_{o}, Q S_{h s c}, Q S_{e s}$ total heat fluxes of the building, hybrid collector and electric energy consumption of the electrical system;

$k$-coefficient of heat transfer via heat pumps.

$S R t_{\text {int }} \& S R_{r}$ values can be considered as constant values, and

$S R_{h w s} \& S R_{i h v}$ values can be regarded as averaged rates.

Variables will be determined by simultaneous differential equations according to the graph based on known dependences (Stoyanov, 2015a, SNiP 23-02-2003, 2004).

Warm period (3):

$$
\begin{gathered}
\frac{d Q S_{\mathrm{hsc}}}{d \tau}=R E ; \quad \frac{d Q S_{0}}{d t}=R_{\mathrm{out}}^{\mathrm{s}}+R_{\mathrm{int}} ; \\
R_{\mathrm{hwss}}=\frac{2}{3} \frac{d Q S_{\mathrm{hsc}}}{d \tau}+k_{\text {ahp }} \frac{d Q S_{\text {ahp }}}{d \tau} ; \\
\frac{d R_{q}}{d \tau}=\frac{2}{3} \frac{d Q S_{\mathrm{hsc}}}{d \tau}-R_{\mathrm{hwss}} ; \\
\frac{d R_{3}}{d \tau}=\frac{1}{3} \frac{d Q S_{\mathrm{hsc}}}{d \tau} ; \quad \frac{d R_{q^{\prime}}}{d \tau}=\frac{d R_{q}}{d \tau} k_{\text {ahp }} ; \\
\frac{d R_{q^{\prime \prime}}}{d \tau}=\frac{d R_{9}}{d \tau} k_{\mathrm{vchp}} ; \quad \frac{d R_{q^{\prime} \mathrm{pw}}}{d \tau}=\frac{d R_{q^{\prime \prime}}}{d \tau} .
\end{gathered}
$$

Cold period (4):

$$
\begin{array}{cc}
\frac{d Q S_{\mathrm{hsc}}}{d \tau}=R E ; & \frac{d Q S_{0}}{d t}=R_{\mathrm{out}}^{\mathrm{w}}-R_{\mathrm{int}} ; \\
R_{\mathrm{hwss}}=\frac{2}{3} \frac{d Q S_{\mathrm{hsc}}}{d \tau} ; & \frac{d R_{\mathrm{E}}}{d \tau}=\frac{1}{3} \frac{d Q S_{\mathrm{hsc}}}{d \tau} ;
\end{array}
$$

$$
\begin{aligned}
\frac{d R_{q \mathrm{pw}}}{d \tau} & =\frac{d R_{\ni}}{d \tau} k_{\mathrm{vchp}} \\
\frac{d R_{E^{\prime}}}{d \tau} & =\frac{d R_{q \mathrm{pw}}}{d \tau},
\end{aligned}
$$

where:

$R_{\text {out }}{ }^{\mathrm{s}}, R_{\text {out }}{ }^{\mathrm{w}}$ - heat inputs into the room through outer fences in the summer period and heat losses through the outer fences in the winter, respectively;

$R$ - ratio of solar radiation average monthly daily quantities entering the inclined and horizontal surfaces;

$E$ - average daily amount of total solar radiation entering the horizontal surface, $\mathrm{MJ} /\left(\mathrm{m}^{2}\right.$ per day $)$.

Solar radiation calculation has been performed based on the methodology presented in the papers (Ghazi, 2015; Khalil, 2016; Amerkhanov, 2006); the accumulating capacity of a geothermal well has been fulfilled based on the papers (Kalinichenko, 2004; Bezhan, 2008; Timakova, 2006). To perform calculations, a control-flow chart and the program implemented in the built-in Microsoft Excel shell has been elaborated.

\section{DISCUSSION AND RESULTS}

Since the heating system based on renewable energy sources is a low-potential one, a warm-air heating system is provided for, which is also utilized by the air conditioning system in summer at the same time. Loads for the heat and cold supply system have been taken in calculations based on consolidated indices (for the city of Stavropol) - structural volume of the building, standard specific heat consumption for heating the buildings (SNiP 23-02-2003, 2004), specific heat-liberation values within the room, including the heat inputs from the Sun (Designer's Handbook. Part I: Heating, 1991), daily rate of hot water consumption (based on the hot water consumption rate for office premises $201 /$ (per day per person) and the average room area per 1 person $\left.-5 \mathrm{~m}^{2}\right)$.

The calculations have been performed for a building with a structural volume of $900 \mathrm{~m}^{3}$ based on the average daily solar radiation indices and climatic features of each design month of a year per two values of hybrid solar collector area of $30 \mathrm{~m}^{2} \&$ $50 \mathrm{~m}^{2}$. The calculation results are shown in Fig. $3 \& 4$, where $S_{\text {o }}$ is the excess amount of the energy (energy shortfall) generated by the system for building energy supply based on the building heat balance, $\mathrm{kWh} /$ day, Qhsc - energy generated by the hybrid solar collector, $\mathrm{kW}^{*} \mathrm{H} / \mathrm{day}, \sum \mathrm{Q}_{\mathrm{acc}}$ - accumulated energy, $\mathrm{kWh} /$ day.

According to calculations performed in accordance with the elaborated graph, the non-uniformity of renewable energy sources utilization throughout the year has significantly decreased based on the developed scheme of the energy complex (line $\sum Q_{\text {acc }}$ in Figures 3 and 4). When selecting the hybrid collector area for the system optimal capacity, the probability of using a backup heat supply source $\left(S_{\mathrm{es}}\right)$ is to be determined by the following formula:

$$
p_{\tau}=1-n_{\tau} / 24+\left(1-\xi_{\tau}\right)
$$

where: $n_{\tau}$ is the number of daylight time hours of the period $\tau$; 
$\xi_{\tau}-$ atmospheric clarity coefficient for the period $\tau$. The clarity coefficient can be determined by the formula $\xi=I_{a} / I_{T i}$, where $I_{a}$ is the total solar radiation on the surface according to the results of long-term observations for the relevant locality; $I_{T i}$ - total solar flux entering on a horizontal area outside the atmosphere during the same period of time to be determined based on the developed calculation program.

\section{$\mathrm{KWh} / \mathrm{day}$}

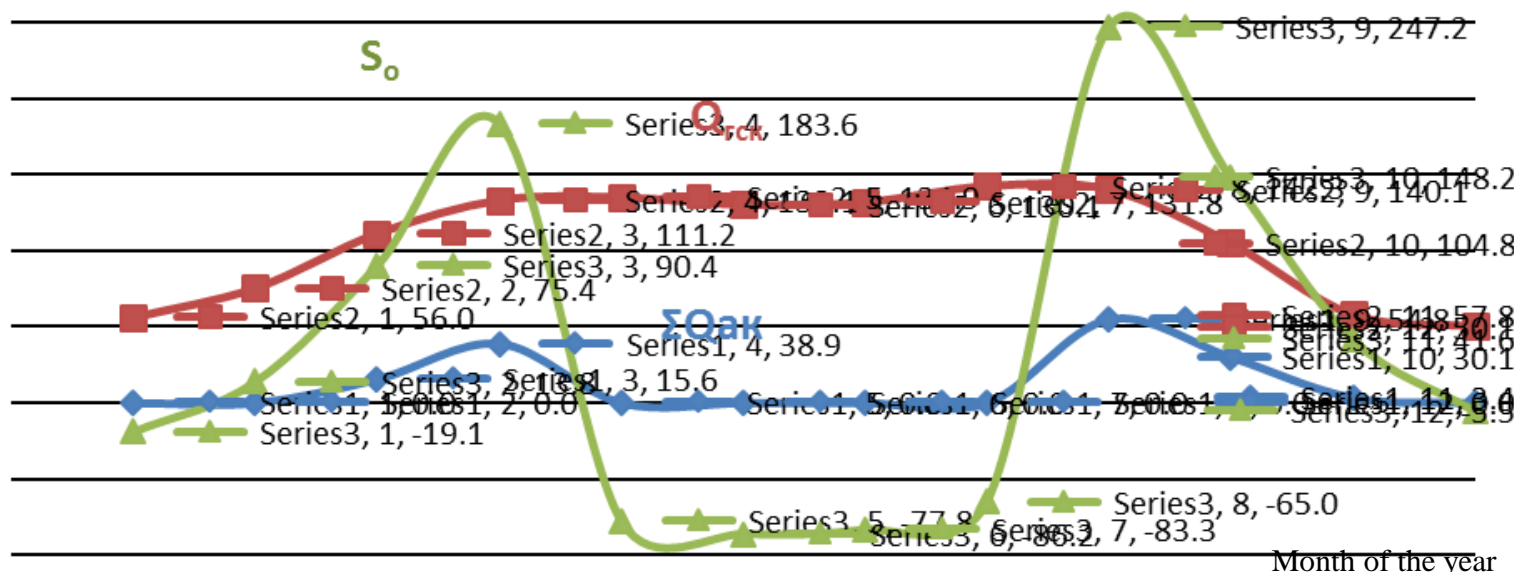

Figure 3. Results of calculating the system of integrated energy supply of separate facilities from renewable energy sources (hybrid solar collector area is $30 \mathrm{~m}^{2}$ )

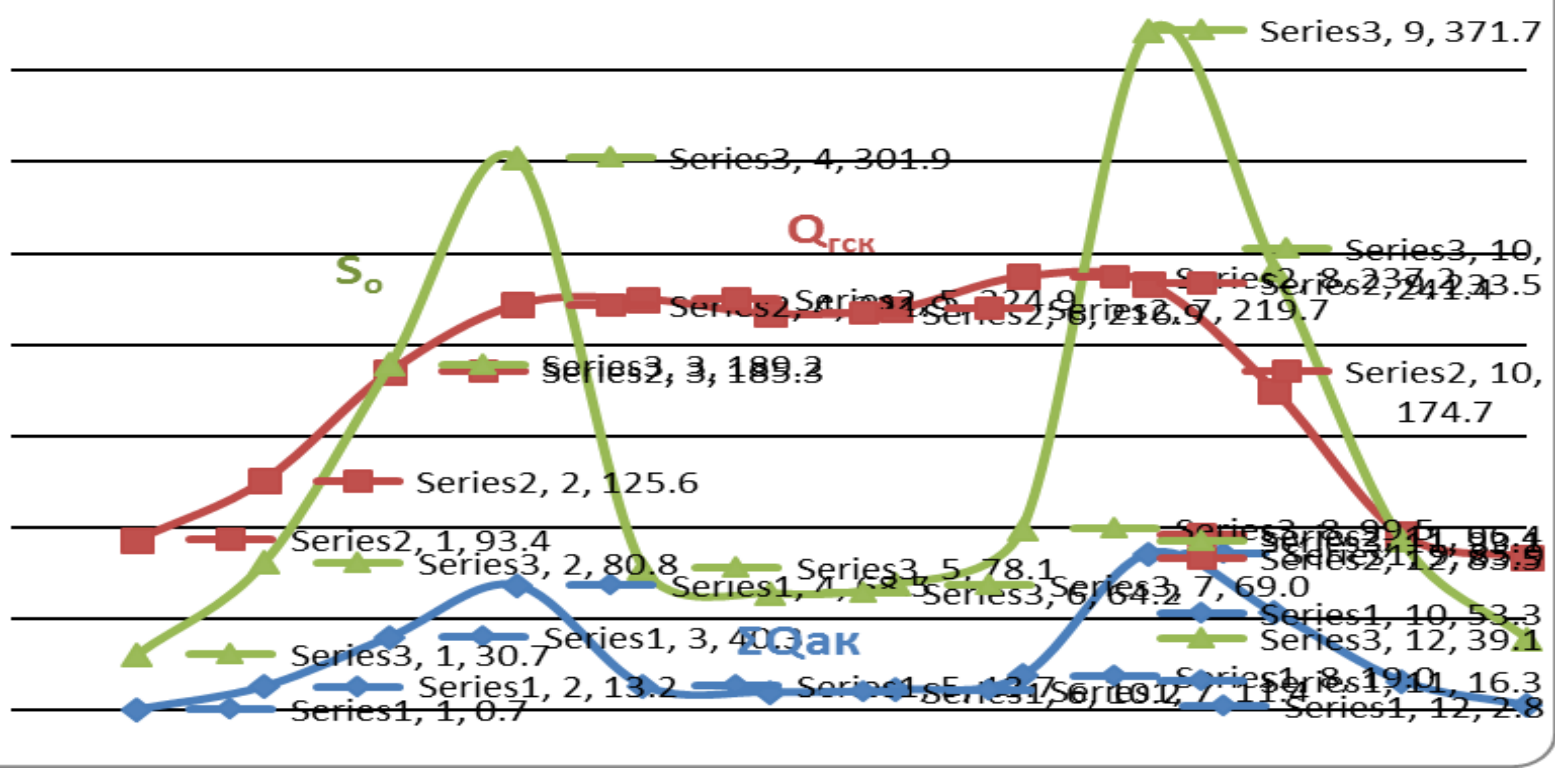

Month of the year

Figure 4. Results of calculating the system of integrated energy supply of separate facilities from renewable energy sources (hybrid solar collector area is $50 \mathrm{~m}^{2}$ ) 


\section{CONCLUSION}

The relevance of the study is due to the possibility of a wider use of ecologically-friendly ubiquitous renewable energy of solar radiation and geothermal sources based on the energy complex developed scheme. Mathematical model of the energy supply system operation from renewable energy sources, developed based on the graph theory, which allows determining the required capacity of the backup electric power source for serving the "peak" loads, as well as for using it in the automatic control system of the designed power complex, is the main research method.

It is shown in the article by the example of calculation that the thermal capacity of the plant intended for providing the heating system with heat increases by $4-7$ times (as well as of the conditioning system in the summer period) and the year-round utilization efficiency of the solar collector rises.

The prospective scope of energy complex application is as follows: sanatorium-and-spa resorts; retail shopping centers; administrative buildings; sport halls; cottages.

\section{REFERENCES}

Russia's energy strategy for the period until 2020. Approved by the Decree of the Government of the Russian Federation as of August 28, 2003 No.1234-r.

Perminov, E.M., 1993. Non-traditional renewable energy sources: the state and prospects for development // Energy construction, No.12, pp. 9-15.

Khavanov, P.A., 2003. Contemporary state of public energy service // Modern systems of heat and gas supply and ventilation: Collected papers / Moscow: Moscow State University of Civil Engineering, pp. 19-22.

Stoyanov, N.I., 2014a. Integrated power supply of separate facilities from solar energy / N.I. Stoyanov, A.I. Voronin, A.G. Stoyanov, A.V. Shagrov. - Stavropol: North-Caucasian Federal University, pp. 96.

Stoyanov, N.I., 2014b. Potential assessment of integrated energy supply of separate facilities from the solar collector / N.I. Stoyanov, A.I. Voronin, A.G. Stoyanov, A.V. Shagrov // International Scientific Journal "Alternative Energy and Ecology," Research and Development Center "TATA", No.13 (153), pp. 12-16.

Boguslavsky, E.I., 1994. Resources of geothermal energy within the territory of Russia and neighboring countries / E.I. Boguslavsky, et al. // International Scientific and Technical Conference "Modern Problems of unconventional energy." Person responsible for release V.V. Elistratov. - St.-Petersburg, pp. 185 .

Gnatus, N.A., 2012. Petrotermal power engineering in Russia. Main trends in the use of non-renewable natural energy resources / N.A. Gnatus. // World Technologies. Moscow: WT No.07(45).
Ryzhenkov V.A., 2009. Concerning the possibility of using the Earth's deep-seated rock heat for electric and heat supply of separate consumers / V.A. Ryzhenkov, N.E. Kutko // Energy saving and water treatment, No.1.

Alkhasov A.B., 2008. Geothermal energy: problems, resources, technologies. Moscow: FIZMATLIT, pp. 376.

Stoyanov, N.I., 2013. Absorption heat pumps in the systems of integrated energy saving of separate facilities from renewable energy sources / N.I. Stoyanov, A.G. Stoyanov // Science. Innovation. Technologies. Scientific Magazine of NorthCaucasian Federal University. - Stavropol: North-Caucasian Federal University, Issue No.4. pp. 51-64.

Designer's Handbook. Part I. Heating / edited by I. G. Staroverova. - Moscow: Stroyizdat, 1991.

Shishkin, N.D., 2004. Combined and effective use of thermal energy sources in autonomous thermal power complexes / Abstract of a thesis for the scientific degree of Doctor of Engineering Science. - Astrakhan.

Pleshka M.S., Vyrlan P.M., Stratan F.I., Bulkin S.G.; Edited by F.I. Stratana. Chisinau: Shtiintsa, 1990. Heat pump solar systems of heating and hot water supply of buildings, $122 \mathrm{p}$.

Sotnikova, K.N., 2009. Combined heat supply systems, combining traditional and renewable energy sources. Abstract of a thesis for a Ph.D. in Engineering Science. - Voronezh, pp. 20.

Stoyanov, N.I., 2015a. Increasing the efficiency of power supply from a hybrid solar collector. Stoyanov, A.I. Voronin, A.G. Stoyanov, A.V. Shagrov // International Scientific Journal "Alternative Energy and Ecology," Research and Development Center "TATA", No.5 (169), pp. 14-18.

Stoyanov, N.I., 2015b. Problems and prospects of using renewable energy sources / N.I. Stoyanov, A.I. Voronin, S.V. Buslov, A.G. Stoyanov, A.V. Shagrov // Contemporary Science and Innovation, No.2 (10), pp. 114-122.

Stoyanov, N.I., 2016. Integrated power supply from solar and petrothermal energy. Theoretical bases and feasibilities / N.I. Stoyanov, A.G. Stoyanov, A.V. Shagrov // Lap LAMBERT Academic Publishing, pp. 9.

A.V. Cherednikova, I.V. Zemlyakova, 2011. Introduction to graph theory. Kostroma: Publishing House of Kostroma State Technological University, pp. 24.

Sidelnikov, V.I., 2004. Methodology of construction and analysis of mathematical models of heat supply systems / Abstract of a thesis for the scientific degree of Doctor of Engineering Science. - Novocherkassk, Cherednikova A.V.

Stoyanov, N.I., 2016. Mathematical model of managing the system of integrated power supply of separate facilities from renewable energy sources / N.I. Stoyanov, S.S. Smirnov, A.G. Stoyanov // Bulletin of the North-Caucasian Federal University, No.1(52), pp. 21-26.

SNiP 23-02-2003. Thermal protection of buildings. M. - 2004. 
Mohammed Kamil Ali Ghazi, 2015. Power plant for heat supply of consumers using solar heaters in the climatic conditions of Iraq / Abstract of a thesis for the scientific degree of Ph.D. in Engineering Science - Novocherkassk.

Ibrahim Ahmed Khalil Ibrahim, 2016. Energy complex for water supply of consumers on the basis of solar converters in the climatic conditions of Iraq / Abstract of a thesis for the scientific degree of Ph.D. in Engineering Science. - Novocherkassk.

Amerkhanov, R.A., 2006. Petrothermal energy in heat supply systems / R.A. Amerkhanov // Heat-process engineering, Vol. 28 , No.2.

Kalinichenko, A.Yu, 2004. Development and research of heataccumulating materials on the basis of liquid paraffins / Abstract of a thesis for the scientific degree of Ph.D. in Engineering Science. - Astrakhan.

Bezhan, A.V., 2008. Regarding the selection of heataccumulating material for the heat accumulator being used in the heat supply system / INDUSTRIAL POWER ENGINEERING No.5.

Timakova, O.V., 2006. Autonomous solar heating and hot water supply system with the use of accumulation based on substances with a phase transition / Abstract of a thesis for the scientific degree of Ph.D. in Engineering Science: 05.14.04. Moscow, pp. 126. 